\title{
Anaphylaxis in an Emergency Department: a Retrospective 10-year Study in a Tertiary Hospital
}

\author{
${ }^{1}$ Serviço de Imunoalergologia, Centro Hospitalar e Universitário de Coimbra, Coimbra, Portugal \\ ${ }^{2}$ Serviço de Medicina Interna, Centro Hospitalar e Universitário de Coimbra, Coimbra, Portugal \\ ${ }^{3}$ Serviço de Medicina Intensiva, Centro Hospitalar e Universitário de Coimbra, Coimbra, Portugal \\ ${ }^{4}$ Serviço de Urgência, Centro Hospitalar e Universitário de Coimbra, Coimbra, Portugal
}

\section{KEY WORDS}

adrenaline; adults; anaphylaxis; complementary treatment; drug; food; iodinated contrast products; insect venom; obesity; treatment

\section{Corresponding author \\ Iolanda Alen Coutinho \\ Centro Hospitalar e \\ Universitario de Coimbra \\ EPE Coimbra, Portugal \\ E-mail: iolandaalen@gmail.com}

Doi

10.23822/EurAnnACI.1764-1489.98

\begin{abstract}
Summary
Background. Anaphylaxis is a potentially fatal medical emergency. The frequency of hospital admissions for anaphylaxis seems to be increasing in the recent decades. Objective. Characterize the patients admitted for anaphylaxis to the adult emergency department (ED) of a tertiary care hospital over a 10-year period, discriminating aetiologies, clinical features and therapy administered. Methods. Retrospective, descriptive and inferential study, evaluating age, sex, Manchester triage system, suspected allergen, site of allergen exposure, comorbidities, cofactors, clinical findings and symptoms, treatment and management. Patients admitted between January 2007 and December 2016 were included. Results. Forty-three patients were enrolled: 23 males, mean age $54.3 \pm 16.2$ years, $n=22$ had history of allergic disease. Two patients were triaged as non-urgent. The most frequently suspected causes of anaphylaxis were: drugs $(33 \%, n=14)$, Hymenoptera venoms $(23 \%, n=10)$, foods $(21 \%, n=9)$ and iodinated contrast products $(12 \%, n=5)$. Adrenaline was used in $88 \%$ of the episodes $(n=38), 55 \%$ of which $(n=21)$ intramuscularly. Mortality was registered in one case. At discharge, adrenaline auto-injector was prescribed in $7 \%(n=3)$ of the patients, and Allergy and Clinical Immunology consultation $(A C I C)$ was requested in $65 \%$ of the episodes $(n=28)$. Statistically significant associations $(p<0.05)$ were established: $a$, anaphylaxis to drugs associated with a low intramuscular adrenaline use and with frequent oxygen therapy; $b$, anaphylaxis to food associated with intramuscular adrenaline administration; $c$, anaphylaxis to Hymenoptera venom associated with male sex; and $d$, anaphylaxis to iodinated contrasts associated with referral to ACIC and with shock. All obese patients developed shock. Conclusions. Anaphylaxis is a life-threatening condition that requires early recognition. Although most patients received adrenaline, administration was not always performed by the recommended route and only a few patients were prescribed adrenaline auto-injector.
\end{abstract}

\section{Introduction}

Anaphylaxis was first described by Charles Richet and Paul Portier in the 20th century and it is considered the maximal variant of immediate type systemic hypersensitivity (1-3). Severe anaphylactic reactions are potentially life-threatening, and their symptoms can vary depending on the organic systems affected (4). Anaphylaxis manifestations usually affect skin and mucosas, but may also involve airway, respiratory, gastrointestinal and/or circulatory disfunction (4-6).

Patients may report to the emergency department (ED) at various stages of the anaphylaxis reaction, with symptoms ranging from urticaria to cardiorespiratory failure (7). Severe reactions may require evaluation in the emergency department, management in intensive care units or hospitalization (8). 
Despite published criteria and guidelines, diagnostic or coding errors are common, as stated in the World Health Organization (WHO) International Classification of Diseases (ICD) (9). Consequently, the underuse or late administration of adrenaline as first-line treatment remains an issue $(10,11)$.

The prevalence and incidence of hospital admissions for anaphylaxis varies widely between studies (13). The incidence of anaphylaxis in the United States of America is 10 to 21 per 100000 person-years, and the estimated prevalence is $1.6 \%(12-14)$. In Europe, reported incidence rates vary from 1.5 to 32 per 100000 person-years and, according to a study of primary healthcare data from the United Kingdom, the annual incidence of anaphylaxis is 8.4 cases per 100000 individuals in the general population $(15,16)$. Many studies have shown that the prevalence of anaphylaxis is increasing, particularly in developed countries (16). The most frequent aetiologies in adults are drugs and Hymenoptera venom (2). However, the correct identification of the causes is not always easy, and often requires referral to specialized consultation for diagnosis and follow-up.

\section{Objective of the study}

The objective of this study was to characterize the aetiologies, the clinical features and the administered treatment in adult patients presenting with anaphylaxis to the ED of the Centro Hospitalar e Universitário de Coimbra (CHUC), Portugal.

\section{Methods}

\section{Type of study}

Retrospective, descriptive and inferential study conducted at the Centro Hospitalar e Universitário de Coimbra (CHUC), Portugal, between January 2007 and December 2016 (10 years).

\section{Patient selection}

Patients were selected using the electronic medical codifications on ED-CHUC software (ALERT ${ }^{\circledR}$ ) to include the International Classification of Disease, Ninth Revision, Clinical Modification (ICD-9 CM) codes: 995.0 (other anaphylactic shock) and 995.6 (anaphylactic shock due to adverse food reaction) (17). Patient files were reviewed, and the criteria for inclusion in the study were adults patients admitted to ED-CHUC with a diagnosis of anaphylaxis as defined by Anaphylaxis: Guidelines from the European Academy of Allergy and Clinical Immunology (4) (see below). A total of 45 cases were identified, two of which were excluded after clinical file revision for not fulfilling anaphylaxis criteria.

The following variables were evaluated: sex, age, year of the episode, site of allergen exposure, site of reaction (out-of-hospital or in-hospital), suspected aetiology, time interval between exposure and allergic reaction, profession, history, comorbidities, cofactors, Manchester triage, clinical manifestations, therapy, need for surveillance, need of intensive care, hospitalization, subsequent referral to Allergy and Clinical Immunology consultation (ACIC), and prescription of adrenaline auto-injector at discharge. Data was collected from the ED records of the anaphylaxis episode. The "suspected allergens" are those so considered by the ED doctors at the anaphylaxis episode report.

\section{Definitions}

The European Academy of Allergy and Clinical Immunology defines anaphylaxis as "a severe, life-threatening generalized or systemic hypersensitivity reaction, which is characterized by being rapid in onset with life-threatening airway, breathing or circulatory problems, and is usually associated with skin and mucosal changes" (4). The presence of shock is defined as systolic blood pressure of $<90 \mathrm{mmHg}$ or $>30 \%$ decrease of the baseline blood pressure (4).

History of allergic disease was collected from the patients' medical records. We considered the World Allergy Organization definition of atopy, a genetic tendency to develop allergic diseases, such as allergic rhinitis, asthma and atopic dermatitis (18). We also considered history of chronic spontaneous urticarial and history of probable allergic reactions to drugs, foods, Hymenoptera, or others.

\section{Statistical analysis}

Statistics were performed using SPSS Statistics version $20.0^{\circledR}$. Descriptive statistics were analysed as mean and standard deviation for the variables with normal distribution, and median and interquartile range for the variables without normal distribution. The variables were described in absolute number (n). The nominal variables were compared using Pearson's chi square test or Fisher's exact test according to Cochran's rules. The normal distribution of the ordinal variables was evaluated using the Kolmogorov-Smirnov test (considering a population sample of more than 30 individuals in both groups). The comparison of these variables was tested using Student's tests (parametric test, applied after verifying the homogeneity of variances by the Levene test) or Mann-Whitney test (non-parametric test). A type I error of 0.05 was considered.

\section{Results}

\section{Clinical presentation}

\section{Epidemiology, triage and site of allergen exposure (out-of-hospitallin-hospital)}

In the 2007-2016 period, 43 cases of anaphylaxis were identified and codified in ED-CHUC, $53 \%(\mathrm{n}=23)$ were male and $47 \%(\mathrm{n}=20)$ female, with a mean age of $54.3 \pm 16.2$ years, and ranging from 23 to 84 years-old. The years of 2014, 2015 and 
2016 had the highest number of registries, $\mathrm{n}=18$, accounting for $42 \%$ of the total population (figure 1).

Considering the Manchester triage criteria, $\mathrm{n}=10$ were classified "red / immediate evaluation", and $\mathrm{n}=22$ were classified "orange / very urgent", these two levels accounting for almost $3 / 4$ of the cases. The remaining patients were classified "yellow / urgent" ( $\mathrm{n}=9)$ or "green / standard evaluation" $(\mathrm{n}=2)$. Most of the anaphylaxis episodes occurred out-of-hospital $(n=31)$, while the remaining occurred inside the hospital, for example during the administration of iodinated contrast for computed tomography scan.

A history of probable allergic disease was found in $\mathrm{n}=22$ (comorbid allergic pathologies are described on table I).

\section{Aetiologies, clinical manifestations and occupational risk}

The suspected causes of anaphylaxis are shown in figure 2. Most anaphylactic reactions $(\mathrm{n}=32)$ were described as immediate

Figure 1 - Number of hospital admissions to ED-CHUC for anaphylaxis per year.

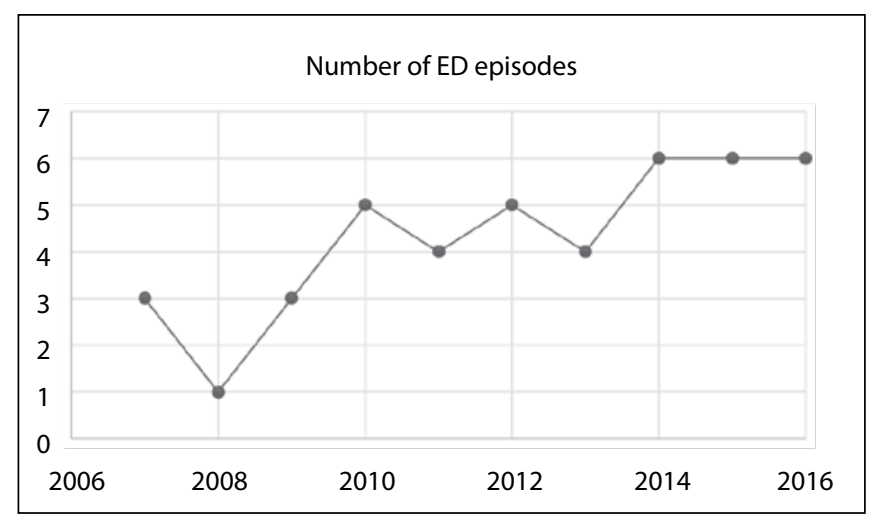

Table I - Comorbid allergic diseases in patients with anaphylaxis admitted to ED-CHUC.

\begin{tabular}{cc}
\hline Comorbid allergic diseases & $\mathrm{n}=22$ \\
\hline allergic asthma & $\mathrm{n}=7$ \\
\hline allergy to beta-lactams & $\mathrm{n}=6$ \\
\hline allergic rhinitis & $\mathrm{n}=5$ \\
\hline chronic spontaneous urticaria & $\mathrm{n}=5$ \\
\hline allergy to non-steroidal anti-inflammatory drugs & $\mathrm{n}=3$ \\
\hline allergy to cow's milk proteins & $\mathrm{n}=3$ \\
\hline anaphylaxis to Hymenoptera sting & $\mathrm{n}=2$ \\
\hline anaphylaxis & $\mathrm{n}=2$ \\
\hline allergy to corticosteroids & $\mathrm{n}=1$ \\
\hline
\end{tabular}

(defined as onset of symptoms less than 1 hour after exposure to the suspected allergen) and the time interval recorded was $<15$ minutes in the majority of these cases $(\mathrm{n}=30)$. In 6 patients the time interval for symptom onset was not recorded. The remaining 5 patients showed intervals between exposure and reaction between 90 to 120 minutes, most of them ( $\mathrm{n}=$ 4) corresponding to cases of suspected food aetiology and 1 to suspected Hymenoptera venom allergy.

One case of biphasic anaphylaxis caused by drugs (tramadol) was registered, with a second peak occurring 12 hours after the first symptoms. In this patient, the late reaction was more severe than the initial reaction: 30 minutes after drug administration the patient developed urticarial rash and dyspnoea, with no therapy or health care assistance in the first phase of the reaction, whereas the late reaction was more severe and included dyspnoea, oropharyngeal tightening, urticarial rash and syncope.

Anaphylaxis was identified due to combinations of dermatological, respiratory and cardiovascular symptoms in $n=17$ patients; dermatological and respiratory symptoms in $\mathrm{n}=6$ patients; respiratory and cardiovascular symptoms in $\mathrm{n}=4$ patients; respiratory, cardiovascular and neurological symptoms in $\mathrm{n}=4$ patients and a combination of dermatological, respiratory, cardiovascular and gastrointestinal in $\mathrm{n}=4$ patients. Anaphylactic shock occurred in 70\% $(\mathrm{n}=30)$ (figure 3).

One case of occupational risk was reported in a forest ranger that suffered anaphylaxis after Hymenoptera stinging.

\section{Comorbidities, cofactors and mortality}

Comorbidities are presented in table II. Possible anaphylaxis co-factors were observed in some patients, namely: medication with angiotensin-converting enzyme inhibitors (ACEI), $\mathrm{n}=19$, with beta-blockers, $\mathrm{n}=5$, and with non-steroidal anti-inflammatory drugs (NSAIDs), $\mathrm{n}=2$; alcohol was a possible cofactor (intake before the anaphylactic episode) in two cases, and one patient had a suspected case of food-dependent exercise-induced anaphylaxis (FDEIA) to wheat.

Intensive care / rapid-response emergency-team was called in $\mathrm{n}$ $=18$ episodes, $\mathrm{n}=7$ required orotracheal intubation, and $\mathrm{n}=5$ had cardiorespiratory arrest. One patient died from anaphylaxis to Hymenoptera venom after multiple stings.

\section{Treatment}

We here analyse together the pre-hospital and the in-hospital therapy registered in patients' medical records. Adrenaline was administered in $\mathrm{n}=38$ cases. The route of administration was intramuscular in $\mathrm{n}=21$, subcutaneous in $\mathrm{n}=13$, intravenous in $\mathrm{n}=5$ and inhaled in $\mathrm{n}=1$. All patients that received intravenous adrenaline had developed anaphylactic shock, including a fatal case of Hymenoptera venom allergy. The single patient that received inhaled adrenaline was an obese and hypertensive patient, that developed anaphylactic shock with severe bron- 
Figure 2 - The most frequent causes of anaphylaxis admitted to ED-CHUC.

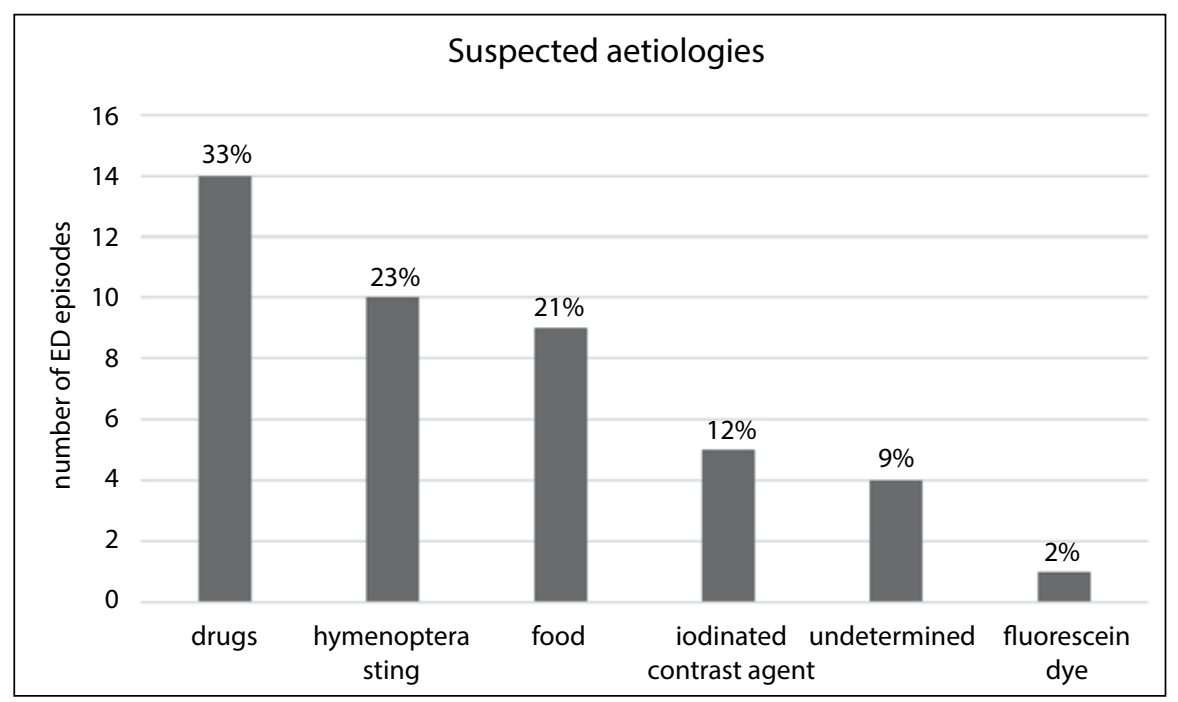

Figure 3 - Signs and symptoms of anaphylaxis in the studied population.

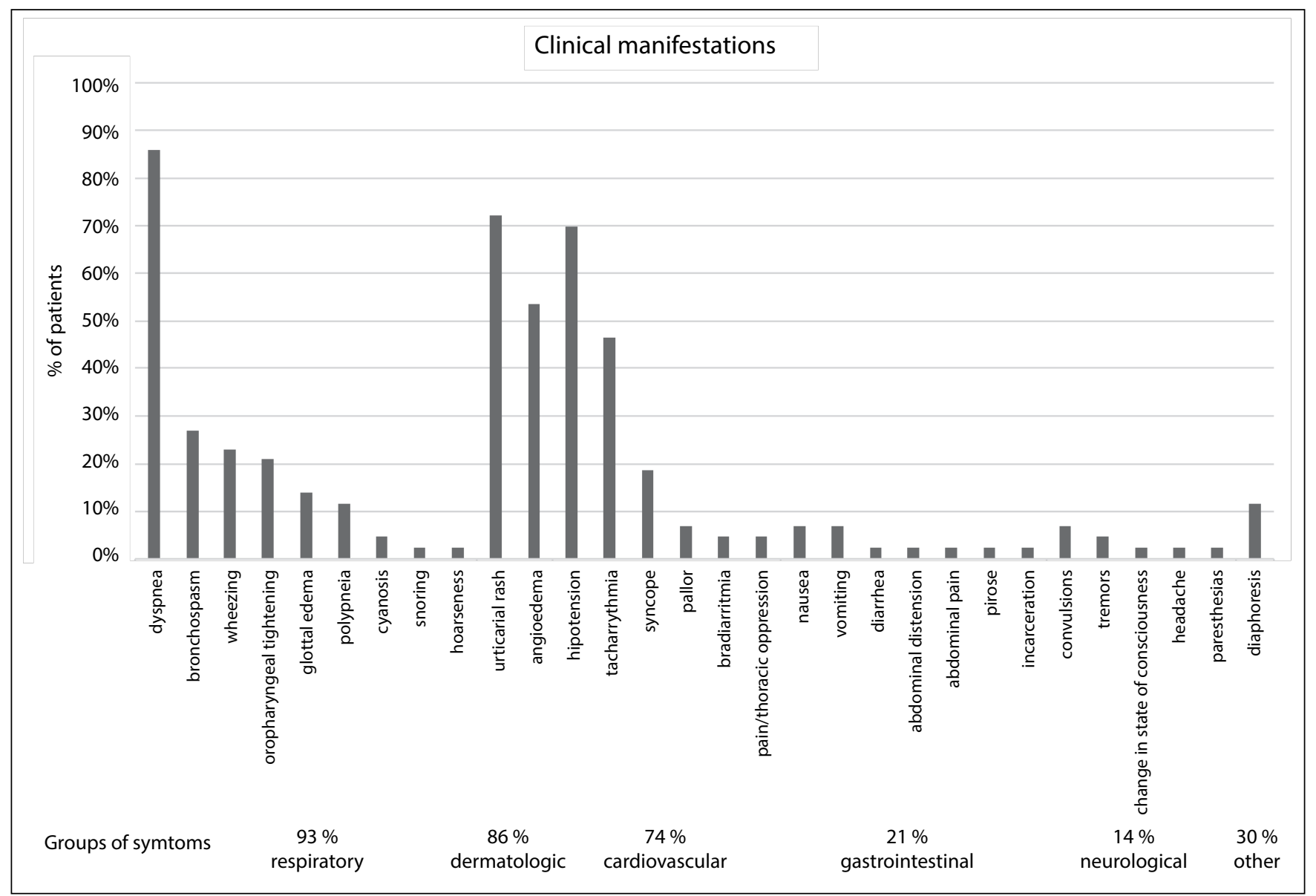


Table II - Comorbidities in the studied population.

\begin{tabular}{cc}
\hline Comorbidities & $\mathrm{n}=35$ \\
\hline arterial hypertension & $\mathrm{n}=22$ \\
\hline obesity & $\mathrm{n}=11$ \\
\hline oncological disease & $\mathrm{n}=10$ \\
\hline alcohol, drug or tobacco abuse & $\mathrm{n}=9$ \\
\hline depression & $\mathrm{n}=8$ \\
\hline non-insulin treated diabetes & $\mathrm{n}=8$ \\
\hline dyslipidaemia & $\mathrm{n}=8$ \\
\hline thromboembolic disease & $\mathrm{n}=5$ \\
\hline cardiac arrhythmias & $\mathrm{n}=3$ \\
\hline sarcoidosis & $\mathrm{n}=3$ \\
\hline thyroid diseases & $\mathrm{n}=3$ \\
\hline chronic obstructive pulmonary disease & $\mathrm{n}=2$ \\
\hline thectious diseases (acquired immunodeficiency syndrome, & $\mathrm{n}=1$ \\
\hline
\end{tabular}

chospasm attributed to diclofenac, suggesting the hypothesis of anaphylaxis associated with a history of respiratory disease exacerbated by anti-inflammatory drugs (AERD). Among the patients that received adrenaline treatment, $\mathrm{n}=30$ received only one dose $(0.5 \mathrm{mg}), \mathrm{n}=5$ two doses, and $\mathrm{n}=3$ three doses.

Regarding other concurrent therapies: $\mathrm{n}=42$ patients were treated with systemic glucocorticoids (median $250.0 \mathrm{mg}$ of methylprednisolone conversion), $\mathrm{n}=32$ received antihistamine H1 therapy (clemastine was the most frequently used); $\mathrm{n}=5$ antihistamine $\mathrm{H} 2$ therapy (ranitidine); $\mathrm{n}=27$ received oxygen therapy (median $2.0 \mathrm{~L} / \mathrm{min}$; IR $10.0 \mathrm{~L} / \mathrm{min}$ ); $\mathrm{n}=35$ received fluid therapy ( $\mathrm{n}=25$ crystalloids, $\mathrm{n}=7$ combination of crystalloids and colloids, and $\mathrm{n}=3$ colloids); and $\mathrm{n}=2$ were given dopamine.

Serum tryptase during the anaphylaxis episode (minimum 1 $\mathrm{h}$ - maximum $6 \mathrm{~h}$ after symptom onset) was evaluated in $\mathrm{n}=$ 4 cases, with values ranging from 32 to $169 \mathrm{mcg} / \mathrm{mL}$ (normal range $<11.4 \mathrm{mcg} / \mathrm{mL}$ ).

The mean time of permanence in the ED was $7.0 \pm 4.0$ hours. Most of the patients were referred for follow-up consultations: allergy and clinical immunology consultation in $\mathrm{n}=28$. Hospitalization was decided in $\mathrm{n}=23$ patients $(\mathrm{n}=19$ in the shortstay hospital unit, $\mathrm{n}=2$ in the allergy and clinical immunology department, $\mathrm{n}=1$ in the intensive care unit, $\mathrm{n}=1$ in the internal medicine department).

CHUC uses an electronic prescription system that allows prescription alerts / limitations. Among the patients with suspected drug allergy (here including drugs, iodinated contrast and fluo-
Table III - Description of the suspected drugs and foods involved in anaphylactic reaction.

\begin{tabular}{|c|c|}
\hline Food & $\mathrm{n}=9$ \\
\hline hellfish and molluscs & $\mathrm{n}=4$ \\
\hline shrimp & $\mathrm{n}=3$ \\
\hline shrimp and squid & $\mathrm{n}=1$ \\
\hline dry fruits & $\mathrm{n}=2$ \\
\hline nut & $\mathrm{n}=1$ \\
\hline hazelnut & $\mathrm{n}=1$ \\
\hline fish & $\mathrm{n}=1$ \\
\hline codfish, hake and tuna & $\mathrm{n}=1$ \\
\hline fresh fruits & $\mathrm{n}=1$ \\
\hline peach & $\mathrm{n}=1$ \\
\hline legumes & $\mathrm{n}=1$ \\
\hline white bean and cabbage & $\mathrm{n}=1$ \\
\hline Drugs & $\mathrm{n}=14$ \\
\hline antibiotics & $\mathrm{n}=4$ \\
\hline amoxicillin-clavulanic acid & $\mathrm{n}=1$ \\
\hline cefazolin & $\mathrm{n}=1$ \\
\hline cefuroxime & $\mathrm{n}=1$ \\
\hline penicillin & $\mathrm{n}=1$ \\
\hline analgesics & $\mathrm{n}=3$ \\
\hline tramadol & $\mathrm{n}=1$ \\
\hline paracetamol & $\mathrm{n}=1$ \\
\hline magnesium metamizole & $\mathrm{n}=1$ \\
\hline non-steroidal anti-inflammatory drugs & $\mathrm{n}=3$ \\
\hline ibuprofen & $\mathrm{n}=1$ \\
\hline diclofenac & $\mathrm{n}=1$ \\
\hline etoricoxib & $\mathrm{n}=1$ \\
\hline anesthetics & $\mathrm{n}=2$ \\
\hline lidocaine & $\mathrm{n}=2$ \\
\hline benzodiazepines & $\mathrm{n}=1$ \\
\hline diazepam & $\mathrm{n}=1$ \\
\hline chemotherapeutic agents & $\mathrm{n}=1$ \\
\hline paclitaxel and carboplatin & $\mathrm{n}=1$ \\
\hline
\end{tabular}

rescein dye), the hospital prescription of the suspected drug was blocked in $n=9 / 20$ of the anaphylaxis episodes.

Adrenaline auto-injector was prescribed at ED discharge in $\mathrm{n}=$ 3 of patients. 


\section{Characteristics of anaphylaxis and relevant clinical associations}

\section{Location}

Regarding the location where anaphylaxis occurred, all suspected food allergies occurred out-of-hospital ( $\mathrm{p}<0.05$, Fisher's exact test). Conversely, in suspected drug allergy, half of the cases of anaphylaxis occurred inside the hospital, and drug allergy corresponded to $58 \%(\mathrm{n}=7 / 12)$ of all in-hospital episodes ( $\mathrm{p}<$ 0.05 , Fisher's exact test), with the remaining attributable to CT contrasts and fluorescein dye.

\section{Professional occupation}

Professions with performance in external environments, such as farmer, mason, forest ranger and fireman were exclusively reported in the group of suspected Hymenoptera venom anaphylaxis.

\section{Suspected causes}

Possible epidemiological differences were found between suspected etiologic groups: all patients with suspected Hymenoptera venom anaphylaxis were male ( $\mathrm{p}<0.05$, Fisher's exact test) whereas all patients with suspected iodinated contrast agent anaphylaxis were female $(p<0.05$, Fisher's exact test). One of the patients with drug anaphylaxis, intravenous magnesium metamizole, had a history of previous metamizole anaphylaxis described in the record of the clinical history of the emergency episode. One patient had a likely diagnosis of food dependent exercise induced anaphylaxis with wheat ingestion, tolerating the ingestion of wheat in the absence of the cofactor. Regarding the Manchester triage, unlike other aetiologies, patients with suspected food allergy anaphylaxis were all classified as severe ( $\mathrm{p}$ $<0.05$, Fisher's exact test).

\section{Shock}

The percentage of patients who developed anaphylactic shock was $70 \%(\mathrm{n}=30)$. The totality of cases with anaphylaxis to iodinated contrast presented with anaphylactic shock were referenced to ACIC ( $p<0.05$, Fisher's exact test). All obese patients developed shock ( $\mathrm{p}<0.05$, Fisher's exact test). All patients with shock had immediate anaphylaxis, and $87.5 \%$ of them initiated symptoms less than 15 minutes after allergen exposure (21 out of the 24 patients with shock and reported time of symptom onset). Patients who developed shock had arterial hypertension in 57\% $(\mathrm{n}=17)$, and were medicated with angiotensin converting enzyme inhibitor in $40 \%$ ( $\mathrm{n}=$ 12). The presence of tachyarrhythmia occurred in $60 \%, n=18$ ( $\mathrm{p}<0.05$, Pearson's chi square) and fluid therapy was required in $90 \%, \mathrm{n}=27(\mathrm{p}<0.05$, Fisher's exact test). Half the patients with shock presented comorbid allergic diseases. Almost all patients with shock, $n=29$, were treated with the first-line therapy adrenaline $(\mathrm{p}<0.05$, Fisher's exact test), by the intramuscular route, $\mathrm{n}=14$, and intravenously, $\mathrm{n}=5$. The only patient treated with inhaled adrenaline was included in this group. Rapid-response emergency-team was called in $n=16$ of anaphylactic shock cases ( $p<0.05$, Pearson's chi square). All patients who presented anaphylaxis due to iodinated contrast agent developed shock.

\section{Treatment}

The suspected causes of the two patients that required dopaminergic support were ibuprofen and cefazolin, and one of them received also intravenous adrenaline. Eleven out of 14 patients with suspected drug related anaphylaxis were treated with oxygen and this group showed significant differences in oxygen flow, with higher flow records.

All patients with suspected food-related anaphylaxis were treated with adrenaline by the recommended IM route $(\mathrm{p}<0.05$ Fisher's exact test), compared with $n=11 / 14$ that received adrenaline in suspected drug allergy, out of which only $3 / 11$ was intramuscularly ( $\mathrm{p}<0.05$, Pearson chi square).

\section{Mortality}

The only fatal case was a patient that developed anaphylactic shock with cardiorespiratory arrest due to multiple Hymenoptera stings (three, one of them in the cervical region). This patient had a previous episode of anaphylaxis due to Hymenoptera venom, about 2 years before the fatal episode and no specialty consultation was performed after the initial episode. This patient had arterial hypertension treated with ACEI. Clinical manifestations were urticaria, angioedema, glottal edema and dyspnoea, about 10-15 minutes after Hymenoptera stingings. In ED, the patient presented with hypotension refractory to fluid therapy and was administered 3 doses of $0.5 \mathrm{mg}$ adrenaline IV, with time intervals of 5 minutes, oxygen and corticosteroid therapy. The patient did not respond to resuscitation and died about one hour after admission (approximately two and a half hours after exposure to venom).

\section{Discussion}

In this study we characterized the clinical manifestations and treatment of patients admitted for anaphylaxis in the ED of a tertiary hospital. Several clinical associations between anaphylaxis manifestations and patients' characteristics were observed. The male preponderance (54\%) in cases of anaphylaxis noted in this study is not consistent with other published studies that cited a slightly higher incidence in females (19-22). We also observed differences in the gender predisposition of different groups of this study, such as, Hymenoptera venom allergy was present only in males, whereas allergy to iodinated contrast agents occurred exclusively in females.

The presence of comorbidities had a clear association with the severity of anaphylaxis in our study. Obesity was strongly associated with severe clinical manifestations and it was present 
in all patients that developed shock. This is concordant with several studies that showed an association between obesity and fatal outcomes $(23,24)$.

The attributable causes of anaphylaxis reported in our study were similar to those reported in the literature for this age group (4): drugs were the main cause, in particular beta-lactam antibiotics. Regarding food allergy, shellfish, in particular shrimp, was the most frequently suspected trigger, contrarily to what was found in other Portuguese studies, in which nuts were the most frequently cited food (25).

Our study included 5 cases of anaphylaxis with onset $>1$ hour after allergen contact. In this group of patients, four had suspected food allergies, in agreement with previous observations that type I hypersensitivity reactions to food may take longer to develop, but usually within 2 hours after ingestion (26).

The treatment discrepancies between suspected food anaphylaxis and suspected drug anaphylaxis is possibly related with the non-recognition of the allergic reaction in drug related cases, as some cases may be interpreted as a non-immunological adverse reaction. The high number of patients with suspected drug related anaphylaxis treated with high oxygen flow therapy may be justified by the fact that most of the reactions occurred inside the hospital.

Regarding anaphylaxis due to Hymenoptera venom allergy, two patients had a previous history of anaphylactic reaction to the same trigger, none of them had previous follow-up in allergy and clinical immunology consultation (and therefore no previous Hymenoptera venom immunotherapy).

An accurate diagnosis of anaphylaxis may be difficult in the emergency department, due to the wide spectrum of clinical presentations and the absence of optimal clinical or laboratorial markers (27). Late diagnosis of anaphylaxis may delay adrenaline administration and result in worse outcomes. Serum tryptase is considered a specific marker of mast cell degranulation, but it is not always elevated during anaphylaxis and laboratorial processing is usually deferred in time $(28,29)$. However, it is the only available marker that supports the diagnosis of anaphylaxis, especially when compared with patient's baseline values (4). In this study, serum tryptase during the anaphylaxis episode was collected only in 4 patients, probably because the clinical presentation was easily recognized on the initial approach, or due to the inability of some ED doctors to add this specific analysis on our ALERT $^{\circledR}$ system.
Intramuscular adrenaline is considered the treatment of choice for anaphylaxis in most anaphylaxis consensus and guidelines $(10,21,30,31)$. However, as also observed in other studies $(12,25)$, there is still a gap in the route of administration of first line therapy: only $\mathrm{n}=21$ patients received adrenaline intramuscularly and $\mathrm{n}=5$ received adrenaline IV (all of which in shock situations), whereas a high proportion of patients were administered subcutaneous adrenaline $(n=13)$.

Despite the long period studied (10 years), only 43 patients were included, at least in part due to the absence of a specific coding for anaphylaxis in ICD-9. ICD-9 has diagnostic codes only for "allergy" and "anaphylactic shock", leaving out the rest of the spectre of anaphylactic reactions (17). This issue is a major concern of allergy scientific societies and is currently being addressed in the forthcoming ICD-11 (31). In addition, it is sometimes difficult for physicians to codify during clinical practice. These reasons may help explain the low number of cases identified and the fact that a large proportion of patients included in our study presented with severe reactions, namely anaphylactic shock.

The limitations of our study include its retrospective nature, the possibility of under-reporting / lack of correct codification, and missing data from incomplete data records. The lack of anaphylaxis codification or incorrect ICD codification has likely limited the number of patients included in the study. Due to the patient selection method, the incidence of anaphylaxis could not be determined.

\section{Conclusions}

Anaphylaxis is a medical emergency and its early recognition and treatment is paramount to prevent fatal outcomes. In this study we evaluated clinical presentation of anaphylaxis, evaluation of its possible causes, treatment and adequate referral in a tertiary hospital centre. Incomplete medical records were frequent and an investment in their improvement would be necessary to obtain more accurate estimates of the burden of anaphylaxis. Obesity was highlighted as an important factor of poor prognosis, as all obese patients developed shock during the anaphylactic reaction.

\section{Conflict of interests}

The authors declare that they have no conflict of interest. 


\section{APPENDIX}

Supplementary table I - Patient characteristics.

\begin{tabular}{|c|c|c|c|c|c|c|c|}
\hline Patient & Age (years) & Gender & Shock & Etiology & Atopy & $\begin{array}{l}\text { Comor- } \\
\text { bidities }\end{array}$ & $\begin{array}{c}\text { Angiotensin } \\
\text { Converting } \\
\text { Enzyme } \\
\text { Inhibitors } \\
\end{array}$ \\
\hline 1 & 63 & male & yes & drug & no & yes & no \\
\hline 2 & 64 & female & no & drug & no & yes & yes \\
\hline 3 & 54 & male & yes & drug & no & yes & no \\
\hline 4 & 56 & male & yes & drug & no & yes & yes \\
\hline 5 & 61 & male & yes & drug & no & yes & yes \\
\hline 6 & 71 & female & yes & drug & no & yes & no \\
\hline 7 & 48 & female & no & drug & no & yes & no \\
\hline 8 & 58 & female & yes & drug & yes & yes & yes \\
\hline 9 & 24 & female & yes & drug & yes & no & no \\
\hline 10 & 55 & female & yes & drug & yes & yes & no \\
\hline 11 & 57 & male & no & drug & yes & yes & yes \\
\hline 12 & 56 & male & yes & drug & yes & yes & no \\
\hline 13 & 79 & female & yes & drug & yes & yes & no \\
\hline 14 & 66 & female & no & drug & yes & yes & no \\
\hline 15 & 73 & male & yes & food & no & yes & yes \\
\hline 16 & 27 & male & no & food & yes & no & no \\
\hline 17 & 82 & female & yes & food & yes & yes & yes \\
\hline 18 & 78 & male & no & food & yes & yes & no \\
\hline 19 & 27 & male & no & food & no & no & no \\
\hline 20 & 43 & female & yes & food & yes & no & no \\
\hline 21 & 84 & female & yes & food & yes & yes & yes \\
\hline 22 & 60 & female & yes & food & yes & yes & yes \\
\hline 23 & 59 & female & no & food & no & yes & yes \\
\hline 24 & 65 & male & yes & dyestuff & no & yes & yes \\
\hline 25 & 61 & male & no & venon & yes & no & no \\
\hline 26 & 52 & male & yes & venon & yes & yes & yes \\
\hline 27 & 44 & male & no & venon & no & no & no \\
\hline 28 & 23 & male & yes & venon & yes & no & no \\
\hline 29 & 42 & male & yes & venon & yes & yes & no \\
\hline 30 & 28 & male & yes & venon & no & no & no \\
\hline 31 & 52 & male & no & venon & yes & yes & yes \\
\hline 32 & 38 & male & yes & venon & no & yes & no \\
\hline 33 & 43 & male & yes & venon & no & yes & no \\
\hline 34 & 55 & male & yes & venon & no & yes & no \\
\hline 35 & 38 & female & yes & iodinated contrast agent & no & yes & no \\
\hline 36 & 64 & female & yes & iodinated contrast agent & no & yes & yes \\
\hline 37 & 62 & female & yes & iodinated contrast agent & no & yes & yes \\
\hline 38 & 73 & female & yes & iodinated contrast agent & no & yes & yes \\
\hline 39 & 68 & female & yes & iodinated contrast agent & yes & yes & yes \\
\hline 40 & 49 & male & no & undetermined & no & yes & no \\
\hline 41 & 23 & female & yes & undetermined & yes & no & no \\
\hline 42 & 49 & female & yes & undetermined & yes & yes & yes \\
\hline 43 & 61 & male & no & undetermined & yes & yes & yes \\
\hline
\end{tabular}




\begin{tabular}{|c|c|c|c|c|c|c|c|c|}
\hline $\begin{array}{c}\text { Non-steroidal } \\
\text { anti-inflammatory } \\
\text { drugs }\end{array}$ & $\begin{array}{c}\text { Beta- } \\
\text { blockers }\end{array}$ & $\begin{array}{l}\text { Physical } \\
\text { exercise }\end{array}$ & Mortality & $\begin{array}{c}\text { Intensive } \\
\text { Care }\end{array}$ & $\begin{array}{c}\text { Dermato- } \\
\text { logical }\end{array}$ & Respiratory & Cardiovascular & Neurological \\
\hline no & no & no & no & No & Yes & Yes & Yes & Yes \\
\hline no & yes & no & no & No & Yes & Yes & No & No \\
\hline no & no & no & no & No & Yes & Yes & Yes & No \\
\hline no & no & no & no & Yes & Yes & Yes & Yes & Yes \\
\hline no & no & no & no & No & No & Yes & Yes & No \\
\hline no & no & no & no & Yes & Yes & Yes & Yes & No \\
\hline no & no & no & no & No & Yes & No & No & No \\
\hline no & no & no & no & No & Yes & Yes & Yes & No \\
\hline no & no & no & no & Yes & Yes & Yes & Yes & No \\
\hline no & no & no & no & Yes & No & Yes & Yes & No \\
\hline no & no & no & no & No & Yes & Yes & No & Yes \\
\hline no & no & no & no & No & Yes & Yes & Yes & Yes \\
\hline no & no & no & no & Yes & Yes & Yes & Yes & No \\
\hline no & no & no & no & Yes & Yes & Yes & No & No \\
\hline no & yes & no & no & Yes & Yes & Yes & Yes & No \\
\hline no & no & no & no & No & Yes & Yes & No & No \\
\hline no & no & no & no & Yes & No & Yes & Yes & No \\
\hline no & no & no & no & No & Yes & Yes & No & No \\
\hline no & no & yes & no & No & Yes & Yes & Yes & No \\
\hline no & no & no & no & Yes & Yes & Yes & Yes & No \\
\hline yes & no & no & no & No & No & Yes & Yes & No \\
\hline no & yes & no & no & Yes & No & Yes & Yes & No \\
\hline no & yes & no & no & No & Yes & Yes & No & No \\
\hline no & no & no & no & Yes & Yes & Yes & Yes & $\mathrm{No}$ \\
\hline no & no & no & no & No & Yes & Yes & No & No \\
\hline no & no & no & yes & Yes & Yes & Yes & Yes & No \\
\hline no & no & no & no & No & Yes & Yes & No & No \\
\hline no & no & no & no & Yes & Yes & Yes & Yes & No \\
\hline no & no & no & no & No & Yes & Yes & Yes & No \\
\hline no & no & no & no & No & Yes & Yes & Yes & No \\
\hline no & yes & no & no & No & Yes & No & No & Yes \\
\hline no & no & no & no & No & Yes & Yes & Yes & No \\
\hline no & no & no & no & Yes & Yes & Yes & Yes & No \\
\hline no & no & no & no & No & No & Yes & Yes & No \\
\hline no & no & no & no & Yes & Yes & Yes & Yes & No \\
\hline no & no & no & no & Yes & Yes & Yes & Yes & $\mathrm{No}$ \\
\hline yes & no & no & no & No & Yes & Yes & Yes & No \\
\hline no & no & no & no & Yes & Yes & Yes & Yes & No \\
\hline no & no & no & no & Yes & Yes & Yes & Yes & No \\
\hline no & no & no & no & No & Yes & Yes & Yes & No \\
\hline no & no & no & no & No & Yes & Yes & Yes & Yes \\
\hline no & no & no & no & No & Yes & No & Yes & No \\
\hline no & no & no & no & No & Yes & Yes & No & No \\
\hline
\end{tabular}




\begin{tabular}{|c|c|c|c|c|c|c|c|}
\hline Patient & $\begin{array}{l}\text { Oxygen } \\
\text { therapy } \\
(\mathrm{L} / \mathrm{min})\end{array}$ & $\begin{array}{l}\text { Orotracheal } \\
\text { intubation }\end{array}$ & $\begin{array}{c}\text { Cardiorespiratory } \\
\text { arrest }\end{array}$ & Fluid Therapy & Anti-H1 & Anti-H2 & $\begin{array}{c}\text { Salbutamol } \\
\text { and/or } \\
\text { Ipratropium } \\
\text { bromide }\end{array}$ \\
\hline 1 & no & no & no & yes & yes & no & no \\
\hline 2 & 10 & no & no & yes & yes & no & yes \\
\hline 3 & 3 & no & no & yes & no & no & no \\
\hline 4 & 4 & no & no & yes & no & no & no \\
\hline 5 & 15 & no & no & yes & yes & yes & yes \\
\hline 6 & 4 & no & no & yes & no & no & yes \\
\hline 7 & no & no & no & no & yes & no & no \\
\hline 8 & 2 & no & no & yes & yes & no & no \\
\hline 9 & 15 & yes & no & yes & no & no & no \\
\hline 10 & 2 & no & yes & yes & no & no & no \\
\hline 11 & 12 & no & no & no & yes & no & yes \\
\hline 12 & 3 & no & no & yes & yes & no & yes \\
\hline 13 & 10 & no & no & no & yes & yes & no \\
\hline 14 & 12 & no & no & yes & yes & no & yes \\
\hline 15 & 2 & no & no & yes & yes & no & no \\
\hline 16 & no & no & no & no & yes & no & no \\
\hline 17 & 2 & no & yes & yes & no & no & no \\
\hline 18 & no & no & no & yes & yes & no & no \\
\hline 19 & 2 & no & no & yes & yes & no & no \\
\hline 20 & 4 & no & no & yes & yes & no & no \\
\hline 21 & 15 & no & no & yes & yes & no & yes \\
\hline 22 & 6 & no & no & yes & yes & yes & no \\
\hline 23 & no & no & no & no & yes & no & yes \\
\hline 24 & 15 & yes & yes & no & yes & no & no \\
\hline 25 & no & no & no & no & yes & no & no \\
\hline 26 & 15 & yes & yes & yes & no & no & no \\
\hline 27 & 2 & no & no & yes & yes & no & no \\
\hline 28 & 3 & no & no & yes & yes & no & no \\
\hline 29 & no & no & no & yes & yes & no & no \\
\hline 30 & no & no & no & yes & yes & yes & yes \\
\hline 31 & no & no & no & yes & no & no & no \\
\hline 32 & no & no & no & yes & yes & no & no \\
\hline 33 & 15 & yes & no & yes & yes & no & no \\
\hline 34 & 2 & no & no & yes & no & no & yes \\
\hline 35 & no & no & no & yes & yes & no & no \\
\hline 36 & 3 & no & no & yes & yes & no & no \\
\hline 37 & no & no & no & yes & no & no & no \\
\hline 38 & 15 & yes & yes & yes & no & no & yes \\
\hline 39 & no & no & no & yes & yes & no & no \\
\hline 40 & no & no & no & yes & yes & no & yes \\
\hline 41 & no & no & no & no & yes & no & no \\
\hline 42 & 3 & no & no & yes & yes & no & no \\
\hline 43 & no & no & no & yes & yes & yes & no \\
\hline
\end{tabular}




\begin{tabular}{|c|c|c|c|c|c|c|c|}
\hline $\begin{array}{l}\text { Intravenous } \\
\text { corticosteroid } \\
\text { therapy }\end{array}$ & $\begin{array}{l}\text { Dopaminergic } \\
\text { support }\end{array}$ & ADR & $\begin{array}{c}\text { ADR } \\
\text { Inhalation }\end{array}$ & $\begin{array}{c}\text { ADR } \\
\text { Intravenous }\end{array}$ & $\begin{array}{c}\text { ADR } \\
\text { Intra } \\
\text { muscular }\end{array}$ & $\begin{array}{c}\text { ADR } \\
\text { Sub } \\
\text { cutaneous }\end{array}$ & $\begin{array}{l}\text { Allergology } \\
\text { and Clinical } \\
\text { Immunology } \\
\text { consultation }\end{array}$ \\
\hline yes & no & no & no & no & no & no & no \\
\hline yes & no & no & no & no & no & no & no \\
\hline yes & no & yes & yes & no & no & no & no \\
\hline yes & no & yes & no & yes & no & no & no \\
\hline yes & no & yes & no & no & yes & no & no \\
\hline yes & no & yes & no & no & no & yes & no \\
\hline yes & no & no & no & no & no & no & yes \\
\hline yes & yes & yes & no & yes & no & no & yes \\
\hline yes & no & yes & no & no & yes & no & yes \\
\hline yes & no & yes & no & no & no & yes & yes \\
\hline yes & no & yes & no & no & no & yes & yes \\
\hline yes & no & yes & no & no & no & yes & yes \\
\hline yes & yes & yes & no & no & no & yes & yes \\
\hline yes & no & yes & no & no & yes & yes & yes \\
\hline yes & no & yes & no & no & yes & no & no \\
\hline yes & no & no & no & no & no & no & yes \\
\hline yes & no & yes & no & no & yes & no & yes \\
\hline yes & no & yes & no & no & yes & no & yes \\
\hline yes & no & yes & no & no & yes & no & yes \\
\hline yes & no & yes & no & no & yes & no & yes \\
\hline yes & no & yes & no & no & yes & no & yes \\
\hline yes & no & yes & no & no & yes & no & yes \\
\hline yes & no & yes & no & no & yes & no & yes \\
\hline yes & no & yes & no & no & yes & no & yes \\
\hline yes & no & no & no & no & no & no & no \\
\hline yes & no & yes & no & yes & no & no & no \\
\hline yes & no & yes & no & no & yes & no & no \\
\hline yes & no & yes & no & yes & no & no & yes \\
\hline yes & no & yes & no & no & yes & no & yes \\
\hline yes & no & yes & no & no & yes & no & yes \\
\hline yes & no & yes & no & no & no & yes & yes \\
\hline yes & no & yes & no & no & no & yes & yes \\
\hline yes & no & yes & no & no & no & yes & yes \\
\hline yes & no & yes & no & no & no & yes & yes \\
\hline yes & no & yes & no & no & yes & no & no \\
\hline yes & no & yes & no & no & yes & no & no \\
\hline yes & no & yes & no & no & no & yes & no \\
\hline yes & no & yes & no & yes & no & yes & no \\
\hline yes & no & yes & no & no & no & yes & yes \\
\hline yes & no & yes & no & no & yes & no & no \\
\hline no & no & yes & no & no & yes & no & yes \\
\hline yes & no & yes & no & no & yes & no & yes \\
\hline yes & no & yes & no & no & yes & no & yes \\
\hline
\end{tabular}




\section{References}

1. Adelman DC, Casale TB, Corren J. Manual of allergy, fifth edition, chapter Immediate Hypersensitivity: Approach to Diagnosis. 2012; 29-51.

2. Ring J, Franz R, Brockow K. Anaphylaxis. Chem Immunol Allergy 2010; 95:190-200. doi: 10.1159/000315952.

3. Brown AF, McKinnon D, Chu K. Emergency Department anaphylaxis: A review of 142 patients in a single year. J Allergy Clin Immunol 2001; 108(5):861-866. doi:10.1067/ mai.2001.119028.

4. Muraro A, Roberts G, Worm M, Bilò MB, Brockow K, Fernández Rivas M, et al. Anaphylaxis: Guidelines from the European Academy of Allergy and Clinical Immunology. Allergy 2014; 69(8):1026-1045. doi:10.1111/all.12437.

5. O'Hehir R, Holgate S, Sheikh A, Middleton. Allergy Essentials, first edition, Elsevier, chapter Anaphylaxis. 2017; 345-360.

6. Reber LL, Hernandez JD, Galli SJ. The pathophysiology of anaphylaxis. J Allergy Clin Immunol 2017; 140(2):335-348. doi:10.1016/j.jaci.2017.06.003.

7. Castilano A, Sternard B, Cummings ED, Shi R, Arnold T, Bahna SL. Pitfalls in anaphylaxis diagnosis and management at a university emergency department. Allergy Asthma Proc 2018; 39(4):316321. doi:10.2500/aap.2018.39.4144.

8. Lakshmanan S, Cuker a. Contemporary management of primary immune thrombocytopenia in adults. J Thromb Haemost 2012; 10(10):1988-1998. doi:10.1111/j.1538-7836.2012.04876.x.

9. Tanno LK, Simons FER, Annesi-maesano I, Calderon MA, Aymé $S$, Demoly P. Fatal anaphylaxis registries data support changes in the who anaphylaxis mortality coding rules. Orphanet J Rare Dis 2017. doi:10.1186/s13023-016-0554-4.

10. Sampson HA, Muñoz-Furlong A, Campbell RL, Adkinson NF Jr, Bock SA, Branum A, et al. Second symposium on the definition and management of anaphylaxis: Summary report - Second National Institute of Allergy and Infectious Disease/Food Allergy and Anaphylaxis Network Symposium. Ann Emerg Med 2006; 47(4):373-380. doi:10.1016/j.annemergmed.2006.01.018.

11. Simons FE, Ardusso LR, Dimov V, Ebisawa M, El-Gamal YM, Lockey RF, et al. World allergy organization anaphylaxis guidelines: 2013 update of the evidence base. Int Arch Allergy Immunol 2013; 162(3):193-204. doi:10.1159/000354543.

12. Techapornroong M, Akrawinthawong K, Cheungpasitporn W, Ruxrungtham K. Anaphylaxis : a ten years inpatient retrospective study, Asian Pac J Allergy Immunol. 2010; 28(4):262-9

13. Wood RA, Camargo CA Jr, Lieberman P, Sampson HA, Schwartz LB, Zitt M, et al. Anaphylaxis in America: The prevalence and characteristics of anaphylaxis in the United States. J Allergy Clin Immunol 2014; 133(2):461-467. doi:10.1016/j.jaci.2013.08.016.

14. Motosue MS, Bellolio MF, Houten HK Van, Shah ND, Campbell RL. Risk factors for severe anaphylaxis in the United States. Ann Allergy, Asthma Immunol. 2017; 119(4):356-361.e2. doi:10.1016/j. anai.2017.07.014.

15. Faria E, Rodrigues-Cernadas J, Gaspar A, Botelho C, Castro E, Lopes A, et al. Drug-Induced Anaphylaxis Survey in Portuguese Allergy Departments. J Investig Allergol Clin Immunol 2014; 24(1):40-48.

16. Panesar SS, Javad S, de Silva D, Nwaru BI, Hickstein L, Muraro A, et al. The epidemiology of anaphylaxis in Europe: A systematic review. Allergy 2013; 68(11):1353-1361. doi:10.1111/all.12272.
17. International Classification of Diseases, ninth revision, Clinical Modification (ICD-9-CM). Available at: http://icd9.chrisendres.com/; 2009.

18. Kase Tanno L, Moises A. Calderon, Helen E. Smith, Sanchez-Borges M, Aziz Sheikh, Pascal Demoly, et al. Dissemination of definitions and concepts of allergic and hypersensitivity conditions. World Allergy Organ J 2016; 9(1):1-9. doi:10.1186/s40413-016-0115-2.

19. Tejedor-Alonso MA, Moro-Moro M, Múgica-García M V. Epidemiology of anaphylaxis: Contributions from the last 10 years. J Investig Allergol Clin Immunol 2015; 25(3):163-175.

20. Tejedor Alonso MA, Moro Moro M, Múgica García MV, Esteban Hernández J, Rosado Ingelmo A, Vila Albelda C, et al. Incidence of anaphylaxis in the city of Alcorcon (Spain): A population-based study. Clin Exp Allergy 2012; 42(4):578-589. doi:10.1111/j.13652222.2011.03930.x.

21. Kemp SF, Lockey RF, Simons FER. Epinephrine: The drug of choice for anaphylaxis. A statement of the world allergy organization. Allergy 2008; 63(8):1061-1070. doi:10.1111/j.13989995.2008.01733.x.

22. Simons FER, Peterson S, Black CD. Epinephrine dispensing patterns for an out-of-hospital population: A novel approach to studying the epidemiology of anaphylaxis. J Allergy Clin Immunol 2002; 110(4):647-651. doi:10.1067/mai.2002.127860.

23. Reitter M, Petitpain N, Latarche C, Cottin J, Massy N, Demoly P, et al. Fatal anaphylaxis with neuromuscular blocking agents: A risk factor and management analysis. Eur J Allergy Clin Immunol 2014; 69(7):954-959. doi:10.1111/all.12426.

24. Turner PJ, Jerschow E, Umasunthar T, Lin R, Campbell DE, Boyle RJ. Fatal Anaphylaxis: Mortality Rate and Risk Factors. J Allergy Clin Immunol Pract 2017; 5(5):1169-1178. doi:10.1016/j. jaip.2017.06.031.

25. Fernandes RA, Regateiro F, Pereira C, Faria E, Pita J, Todo-Bom A, et al. Anaphylaxis in a food allergy outpatient department: Oneyear review. Eur Ann Allergy Clin Immunol 2018; 50(2):81-88. doi:10.23822/EurAnnACI.1764-1489.45.

26. Muraro A, Werfel T, Hoffmann-Sommergruber K, Roberts G, Beyer K, Bindslev-Jensen C, et al. EAACI Food Allergy and Anaphylaxis Guidelines: Diagnosis and management of food allergy. Allergy 2014; 69(8):1008-1025. doi:10.1111/all.12429.

27. Alvarez-Perea A, Ameiro B, Morales C, Zambrano G, Rodríguez A, Guzmán M, et al. Anaphylaxis in the Pediatric Emergency Department: Analysis of 133 Cases After an Allergy Workup. J Allergy Clin Immunol Pract 2017; 5(5):1256-1263. doi:10.1016/j. jaip.2017.02.011.

28. Schwartz LB. Diagnostic Value of Tryptase in Anaphylaxis and Mastocytosis. Immunol Allergy Clin North Am 2006; 26(3):451463. doi:10.1016/j.iac.2006.05.010.

29. Sala-Cunill A, Cardona V, Labrador-Horrillo M, Luengo O, Esteso O, Garriga T, et al. Usefulness and limitations of sequential serum tryptase for the diagnosis of anaphylaxis in 102 patients. Int Arch Allergy Immunol 2013; 160(2):192-199. doi:10.1159/000339749.

30. Koscove E. Symposium on the Definition and Management of Anaphylaxis. Ann Emerg Med 2006; 48(6):762. doi:10.1016/j. annemergmed.2006.06.052.

31. Sicherer SH, Simons FER. Epinephrine for First-aid Management of Anaphylaxis. Pediatrics 2017; 139(3):e20164006. doi:10.1542/ peds.2016-4006. 